\title{
Influência da adubação no crescimento e no desenvolvimento de Salvia splendens
}

\author{
Influence of fertilization on Salvia splendens growth and development \\ Influencia de la fertilización en el crecimiento y desarrollo de Salvia splendens
}

Recebido: 12/01/2021 | Revisado: 21/01/2021 | Aceito: 25/01/2021 | Publicado: 31/01/2021

Cristian José Steffens
ORCID: https://orcid.org/0000-0002-0459-4753
Instituto de Desenvolvimento Educacional de Passo Fundo, Brasil
E-mail: cristiansteffens14@gmail.com
Leonita Beatriz Girardi
ORCID: https://orcid.org/0000-0003-2035-2866
E-mail: lbgirardi@ @ hotmail.com
Janine Farias Menegaes
ORCID: https://orcid.org/0000-0001-6053-4221
Universidade Federal de Santa Maria, Brasil
E-mail: janine_rs@ hotmail.com
Daniela Machado Monteiro
ORCID: https://orcid.org/0000-0002-9396-8453
E-mail: machadodaniela63@live.com
Ítalo Girardi Ferreira
Instituto de Desenvolvimento Educacional de Passo Fundo, Brasil
ORCID: https://orcid.org/0000-0002-0984-6577
Universidade de Passo Fundo, Brasil
E-mail: italogf@ icloud.com

\begin{abstract}
Resumo
$\mathrm{O}$ presente trabalho tem como objetivo avaliar a influência do substrato e da adubação no desenvolvimento e qualidade de mudas de alegria-de-jardim (Salvia splendens Ker Gawl.). Adotou-se o delineamento inteiramente casualizado, com quatro tratamentos constituídos de diferentes métodos de adubação sendo: T1 - testemunha; T2 adubação por fertirrigação; T3 - adubação foliar e T4 - adubação por fertirrigação + foliar, com cinco repetições sendo cada unidade experimental composta de quatro mudas. As mudas foram transplantadas em bandejas de 15 alvéolos com substrato turfa, as adubações foram realizadas em três etapas semanalmente a partir do transplante. Avaliou-se a altura de plantas, espessura do caule, número de folhas, comprimento e massa verde radicular e coesão de torrão, através de escalas de notas de 1 a 5. Observou-se que a altura de plantas foi maior no tratamento T4, todavia, neste tratamento as plantas estavam estioladas. As características avaliadas das raízes tiveram melhor desempenho nos tratamentos TI e T2, assim como melhor coesão de torrão; as mudas com adição de adubação por fertirrigação apresentam maior uniformidade de bandeja tanto em tamanho. Desta forma, recomenda-se a adubação por fertirrigação para a produção de mudas de alegria-de-jardim.
\end{abstract}

Palavras-chave: Salvia splendens Ker Gawl.; Flores anuais; Nutrição de plantas; Substrato.

\begin{abstract}
The present work aims to evaluate the influence of substrate and fertilization on the development and quality of seedlings of garden joy (Salvia splendens Ker Gawl.). A completely randomized design was adopted, with four treatments consisting of different fertilization methods: T1 - control; T2 - fertilization by fertigation; T3 - foliar fertilization and T4 - fertilization by fertigation + foliar, with five replications, each experimental unit being composed of four seedlings. The seedlings were transplanted in trays of 15 wells with peat substrate, fertilization was carried out in three stages weekly from the transplant. Plant height, stem thickness, number of leaves, length and root green mass and clod cohesion were evaluated using scales from 1 to 5. It was observed that the plant height was higher in the T4 treatment, however, in this treatment the plants were isolated. The evaluated characteristics of the roots had better performance in the TI and T2 treatments, as well as better clod cohesion; seedlings with the addition of fertilization by fertigation show greater tray uniformity in both size. In this way, fertilization by fertigation is recommended for the production of seedlings of garden joy.
\end{abstract}

Keywords: Salvia splendens Ker Gawl.; Annual flowers; Plant nutrition; Substrate.

\section{Resumen}

El presente trabajo tiene como objetivo evaluar la influencia del sustrato y la fertilización en el desarrollo y la calidad de las plántulas de la alegría del jardín (Salvia splendens Ker Gawl.). Se adoptó un diseño completamente al azar, con 
cuatro tratamientos que consistieron en diferentes métodos de fertilización: T1 - control; T2 - fertilización por fertirrigación; T3 - fertilización foliar y T4 - fertilización por fertirrigación + foliar, con cinco repeticiones, estando cada unidad experimental compuesta por cuatro plántulas. Las plántulas se trasplantaron en bandejas de 15 pozos con sustrato de turba, la fertilización se realizó en tres etapas semanales desde el trasplante. La altura de la planta, el grosor del tallo, el número de hojas, el largo y la masa verde de la raíz y la cohesión del terrón se evaluaron utilizando escalas de 1 a 5 . Se observó que la altura de la planta fue mayor en el tratamiento T4, sin embargo, en este tratamiento se aislaron las plantas. Las características evaluadas de las raíces tuvieron mejor comportamiento en los tratamientos TI y T2, así como mejor cohesión del terrón; las plántulas con la adición de fertilización por fertirrigación muestran una mayor uniformidad de bandeja en ambos tamaños. De esta forma, se recomienda la fertilización por fertirrigación para la producción de plántulas de alegría de jardín.

Palabras clave: Salvia splendens Ker Gawl.; Flores anuales; Nutrición vegetal; Sustrato.

\section{Introdução}

A produção comercial de flores vem crescendo a cada ano, e se difundindo nas mais distintas regiões brasileiras, para Fresinghelli Neto (2018), a floricultura é um ramo que denota a variedade no cultivo, além de diversas formas de utilização na sociedade, na condição de atividade agrícola, vem tomando espaço no mercado como uma prática rentável e geradora de empregos diretos e indiretos, além de exigir do produtor um alto grau de profissionalização e tecnificação, sendo um mercado bastante competitivo.

No Brasil, tanto a produção como o consumo de flores e plantas ornamentais tem acompanhando as tendências do mercado mundial, com crescimento anual na faixa de $8 \%$. Esse mercado apresenta alto valor comercial de seus produtos, em função do ciclo de cultivo das flores e plantas ornamentais ser relativamente curto, existe a possibilidade de um rápido retorno econômico, além do valor comercial dos produtos da floricultura ser normalmente elevado, em comparação com hortaliças e frutas, por exemplo (Terra \& Züge, 2013; Junqueira \& Peetz, 2017).

O Rio Grande do Sul, possui alguns polos de produção, no entanto, é autossuficiente apenas em flores anuais ou caixarias, este nome se deve a forma como são comercializadas essas flores, em caixas com 15 mudas, geralmente, em embalagem plástica. O setor de caixaria tem se desenvolvido pela rapidez de produção, maior facilidade de venda direta ao consumidor, além de abranger um grande número de espécies, em que a qualidade das mudas é primordial (Bellé, 2011; Girardi et al., 2012; Piroli, 2018).

De acordo com Bellé (2011), existe em cultivo mais de 70 espécies de flores anuais, seu valor ornamental está na diversidade de cores, formas e beleza das flores, que forram os canteiros formando tapetes coloridos, as mesmas são divididas em dois grupos de cultivo em função da melhor época de cultivo nas condições climáticas brasileiras, sendo espécies de outono/inverno e de primavera/verão. As principais espécies, mais produzidas e comercializadas de outono/inverno para o sul do país são: boca-de-leão (Anthirrinum majus Linn); amor-perfeiro (Viola x wittrockiana W. Gans), cravina-chinesa (Dianthus chinensis L.), flor-de-mel (Lobularia maritimum Desv.), lobélia (Lobelia erinus Linn), e as de primavera/verão se destacam: alegria-de-jardim (Salvia splendens Ker Gawl.), cravo-de-defunto (Tagetes patula Linn e T. erecta Linn), begônia (Begonia semperflorens Willd.), beijinho (Impatiens walleriana Hook.f), torenia (Torenia fournieri Linden ex E.Fourn), entre outras (Bellé, 2011; Lorenzi, 2013).

Entre as espécies de forrações anuais ornamentais, destacam a alegria-de-jardim (Salvia splendens), em que suas flores são dispostas em espiga terminal de vários tons de colorações creme, rosa, roxo, bicolores a vermelho, esta última coloração é a preferida pelos consumidores. A espécie pertence à família Lamiaceae, atingindo até 0,30 m de altura, é originária do Brasil, com propagação por sementes, seu uso em jardins se dá em virtude da sua intensa floração durante todo o ano (Lorenzi, 2013).

Na produção de flores anuais em caixaria a relação de substratos-recipiente (vaso, embalagem ou bandeja) é de suma importância. De acordo com Kämpf et al. (2006), o desenvolvimento de raízes em recipiente é diferente daquele do campo, 
assim, cultivos em recipientes alteram as condições entre as raízes e o substrato em razão do volume e espaços reduzidos. Nesse sentido, o substrato se torna um componente de extrema importância e deve ser cuidadosamente escolhido pelas suas características físicas, químicas e biológicas.

O cultivo em recipientes requer irrigações e fertilizações frequentes e, para tanto, faz-se necessário o conhecimento das suas propriedades às quais são fatores determinantes no manejo e controle de qualidade dos cultivos. Entre os substratos, Schmitz et al. (2002) verificaram que a turfa apresenta valores para as características físicas e químicas mais próximo ao ideal para um substrato com maior teor de matéria orgânica. Outro fator importante é a determinação da densidade do substrato, que relacionada a massa e volume diretamente, Kämpf et al. (2006) consideram uma densidade ideal para substratos hortícolas está entre 400 e $500 \mathrm{~kg} \mathrm{~m}^{-3}$. Com o sistema de cultivo em substrato, também, é possível contornar condições desfavoráveis, comumente enfrentadas com o cultivo tradicional em solo, como a baixa fertilidade química, impedimentos físicos, além de problemas com salinização, incidência de pragas e doenças, contaminações diversas, entre outras (Costa, 2003).

De acordo com Caballero et al. (2007), a disponibilidade de nutrientes é um dos fatores essenciais que exercem a adequação de substratos orgânicos para o crescimento das plantas. Essa disponibilidade pode não depender apenas da composição do substrato, mas também da capacidade de adsorção, do $\mathrm{pH}$, da estabilidade biológica e da presença de compostos orgânicos dissolvidos. Segundo Pires et al. (2008) a função do substrato é dar sustentação às plantas, proporcionar o crescimento das raízes e fornecer as quantidades adequadas de ar, água e nutrientes. Tais parâmetros são observados na germinação, e exerce grande influência sobre a emergência das plântulas e formação das mudas.

Para a produção de plantas com atrativo ornamental, seja nas folhas ou nas flores, o estado nutricional em equilíbrio resulta em plantas de alta qualidade comercial. Segundo Alvarez et al. (2014), a importância da dose correta e dos teores de nutrientes dos fertilizantes são fundamentais em todas as etapas produtivas, desde a semeadura até a colheita destes produtos, uma vez que para o crescimento e desenvolvimento das plantas é preciso um adequado balanço nutricional, sendo que cada nutriente possui uma função dentro das plantas.

Segundo Ludwig et al. (2013), o cultivo em recipiente com substrato limita o espaço disponível ao sistema radicular, o que implica no fornecimento de nutrientes, que deve ser preciso, porém, com a suplementação insuficiente desses, as culturas rapidamente apresentam sintomas de deficiência. Nesse sentido o substrato deve apresentar uma relação adequada de água e ar para suprir as necessidades das plantas, além de apresentar baixa densidade e ser rico em nutrientes (Kämpf et al., 2006).

Diante do exposto o presente trabalho tem como objetivo avaliar a influência do substrato e da adubação no desenvolvimento e qualidade de mudas de alegria-de-jardim (Salvia splendens Ker Gawl.).

\section{Metodologia}

O experimento foi realizado na Floricultura Cantinho das Flores, no Primeiro Distrito de Victor Graeff, Rio Grande do

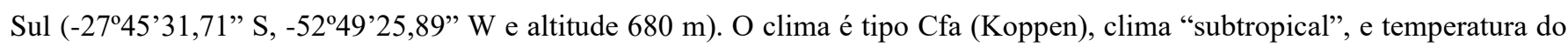
mês mais quente maior que $20^{\circ} \mathrm{C}$ e mais fria de menor que $10^{\circ} \mathrm{C}$, pelo período de agosto a novembro de 2020 .

Adotou-se o delineamento inteiramente casualizado, com quatro tratamentos constituídos de diferentes métodos de adubação sendo: T1: testemunha (sem adubação); T2: adubação por fertirrigação com Fertilizante Misto Hakaphos Vermelho ${ }^{\circledR}$ (NPK 18-18-18), conforme recomendação do fabricante $2 \mathrm{~kg} \mathrm{ha}^{-1}$, adaptado a área da bandeja a dose foi de $20 \mathrm{~g} \mathrm{~L}^{-1}$ de água, com aplicação por regador crivo fino; T3: adubação foliar com produto comercial Biosul ${ }^{\circledR}$ Fertilizantes (NPK 08-05-08), conforme recomendação do fabricante e adaptado a área da bandeja a dose foi de $20 \mathrm{~mL} \mathrm{~L}^{-1}$ de água, com aplicação via borrifador crivo fino; e T4: adubação por fertirrigação + foliar. Com cinco repetições sendo cada unidade experimental composta de quatro mudas. 
As mudas foram adquiridas da Empresa Úrsula, localizada em Nova Petrópolis, RS, sendo que as mesmas são comercializadas em plugs, com altura uniforme de $1,5 \mathrm{~cm}$ (Figuras 1 a e $1 \mathrm{~b}$ ). Na sequência, as mudas foram transplantadas para as bandejas definitivas, bandejas essas de plástico preto com 15 alvéolos com substrato turfa pura, proveniente do município de Araranguá Santa Catarina/SC.

As adubações foram realizadas em três etapas, sendo aos 8; 15 e 22 oito dias após o transplante (DAT) em todos os tratamentos exceto na testemunha. Realizou-se irrigações diárias, via regador crivo fino, com aproximadamente $3 \mathrm{~mm}$ de lâmina de água $\left(3 \mathrm{~L} \mathrm{~m}^{-2}\right)$.

As variáveis analisadas foram: altura de plantas $(\mathrm{cm})$ com auxílio de régua milimetrada, excluindo a inflorescência, espessura do caule $(\mathrm{mm})$ com auxílio de um paquímetro $(0,001)$, número de folhas abertas de contagem manual, comprimento radicular $(\mathrm{cm})$ com régua milimetrada (Figura $1 \mathrm{e}$ ), massa verde de raiz $(\mathrm{g})$ com auxílio de balança $(0,001 \mathrm{~g})$, homogeneidade da bandeja (aspectos em relação ao tamanho de todas as mudas e floração) realizada visualmente e coesão de torrão, através de notas.

Figura 1 - Mudas de alegria-de-jardim (Salvia splendens Ker Gawl.). a: bandeja com plugs, b: plugs, c: mudas transplantadas, d: mudas em ponto de avaliação para número de folhas, e: mudas para avaliação do sistema radicular. T1, T2, T3 e T4: tratamentos supracitados. Fonte: Autores (2020).

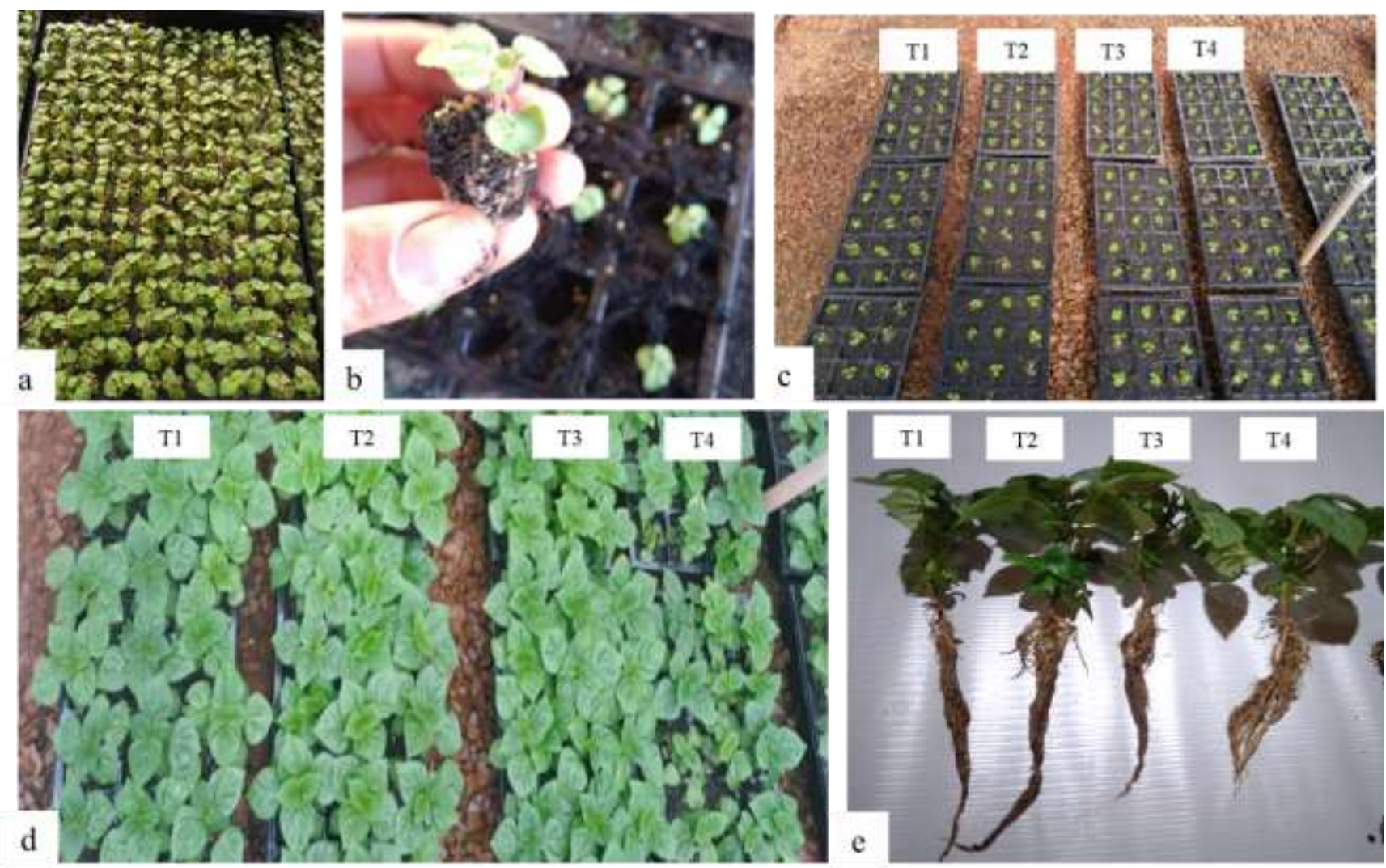

Fonte: Autores.

Foram atribuídas notas de 1 a 5 (Figura 2), em que a nota 1 correspondente ao substrato que apresenta a mais baixa estabilidade e a nota 5 àquele de melhor estabilidade, conforme descrito a seguir: Nota 1: Baixa estabilidade, acima de 50\% do torrão fica retido no recipiente, e o torrão não permanece coeso; Nota 2: Entre 10\% e 30\% do torrão fica retido no recipiente, sendo que o torrão não permanece coeso; Nota 3: O torrão se destaca do recipiente, porém não permanece coeso; Nota 4: O 
torrão se destaca do recipiente, mas há uma perda de até $10 \%$ do substrato; Nota 5: Todo o torrão é destacado do recipiente e mais de $90 \%$ dele permanece coeso (Menegaes et al., 2017).

Figura 2 - Escala de notas da estrutura do torrão. Fonte: adaptado de Menegaes et al. (2017).

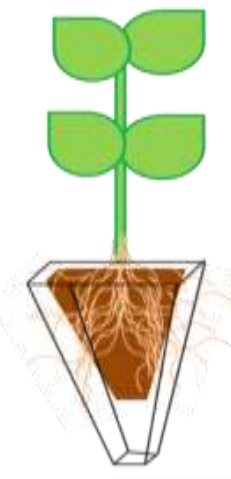

1

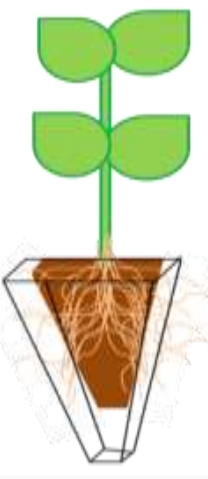

2

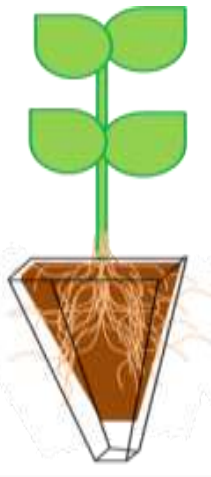

3

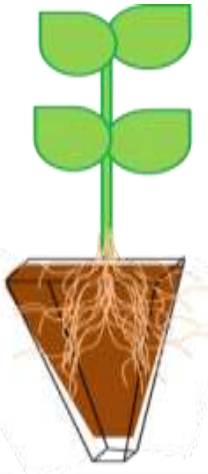

4

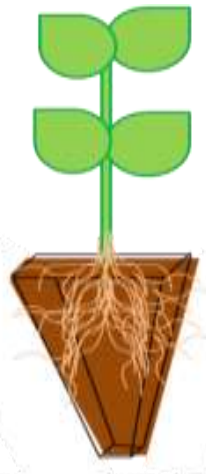

5

Fonte: Autores.

Os dados expressos em percentagem foram transformados em arco-seno $\sqrt{\mathrm{x} / 100}$ e as análises de variância (ANOVA) e a comparação das médias pelo teste de Turey $(\mathrm{p}<0,05)$, foram realizadas com o auxílio do programa estatístico SISVAR (Ferreira, 2014).

\section{Resultados e Discussão}

Na Tabela 1, expõe o resultado para a variável altura de plantas, onde observou-se que o T4 se diferiu dos demais tratamentos. Tal resultado pode ser explicado pelo fato de ser esse tratamento com a aplicação das duas formulações de adubação ocorrer em conjunto, todavia, essas plantas ao receberem doses elevadas de fertilizantes tenderam ao estiolamento, por observação visual, o que não é vantajoso para as flores anuais, pois se busca plantas mais compactas para que as mesmas cumpram realmente seu papel que é de forrar o solo quando implantadas nos canteiros. Para Bellé (2011), na maioria das vezes em produção comercial é colocado redutor de crescimentos nas mudas de forrações para que as mesmas permanecem baixas, entre 10 a $15 \mathrm{~cm}$ dependendo da espécie.

Feletti (2018) trabalhando com mudas de espécies florestais em viveiros com diferentes tamanhos de tubetes, esclarece que o crescimento em altura de mudas está ligado intimamente a processos fisiológicos da planta, e ainda, que há fatores externos que podem interagir dificultando seu crescimento, onde a aplicação de doses insuficientes ou excessivas de fertilizantes, podem gerar efeitos negativos ao crescimento das plantas, provocando queda de sua produtividade.

Resultados semelhantes foram encontrados por Ludwig et al. (2013), avaliando a resposta de plantas de amor-perfeito quando submetido a diferentes doses de adubo nitrogenado, relata que a fertilidade do substrato utilizado para a produção das espécies ornamentais é de grande importância, a fim de poder propiciar o crescimento acelerado das mesmas, com boas características nutricionais, o que leva a beleza visual, resistência a doenças, florescimento precoce e por maiores períodos.

Para o número de folhas (Tabela 1), o tratamento T2 apresentou o maior número de folhas diferindo dos demais, o tratamento que apresentou o menor valor foi o com adição de adubação foliar, indicando a necessidade de adubação via solo/substrato (Figura 1d). O maior número de folhas em uma planta significa maior translocação de assimilados fotossintéticos para a planta, de acordo com Lopes et al. (2007), o número de folhas é um dos parâmetros mais importantes na 
avaliação do crescimento das plantas, pois sua determinação adequada durante o ciclo da cultura possibilita modelar o crescimento e o desenvolvimento das plantas e, em consequência, a produtividade e a produção total da cultura.

Tabela 1 - Altura de plantas, número de folhas, espessura do caule, comprimento e massa fresca radicular e notas do torrão de alegria-de-jardim (Salvia splendens Ker Gawl.).

\begin{tabular}{cccc}
\hline Tratamentos & Altura de plantas $(\mathrm{cm})$ & $\begin{array}{c}\text { Número de folhas } \\
\text { (unid.) }\end{array}$ & $\begin{array}{c}\text { Espessura do caule } \\
(\mathrm{mm})\end{array}$ \\
\hline T1 - testemunha (sem adubação) & $4,9 * \mathrm{~b}$ & $7,2 * \mathrm{~b}$ & $2,8 * \mathrm{~b}$ \\
T2 - adubação por fertirrigação & $5,1 \mathrm{~b}$ & $10,5 \mathrm{a}$ & $5,6 \mathrm{a}$ \\
T3 - adubação foliar & $5,8 \mathrm{~b}$ & $7,0 \mathrm{c}$ & $6,2 \mathrm{a}$ \\
T4 - adubação por fertirrigação + foliar & $8,2 \mathrm{a}$ & $8,5 \mathrm{~b}$ & $3,7 \mathrm{~b}$ \\
Média & 6,0 & 8,3 & 4,6 \\
\hline CV (\%) & 6,49 & 4,94 & 9,04 \\
\hline Comprimento radicular & Massa fresca radicular & Notas do torrão \\
\hline T1 - testemunha (sem adubação) & $(\mathrm{cm})$ & $(\mathrm{g})$ & $4,5 * \mathrm{~b}$ \\
T2 - adubação por fertirrigação & $18,5 * \mathrm{a}$ & $3,1 * \mathrm{a}$ & $5,0 \mathrm{a}$ \\
T3 - adubação foliar & $17,0 \mathrm{a}$ & $2,7 \mathrm{~b}$ & $3,8 \mathrm{c}$ \\
T4 - adubação por fertirrigação + foliar & $10,6 \mathrm{~b}$ & $1,3 \mathrm{c}$ & $2,0 \mathrm{~d}$ \\
Média & $11,8 \mathrm{~b}$ & $1,6 \mathrm{c}$ & 3,8 \\
\hline CV $(\%)$ & 14,5 & 2,2 & 8,91 \\
\hline
\end{tabular}

* interação significativa entre os tratamentos. Teste de médias não seguidas pela mesma letra diferem pelo teste Tukey ( $<<0,05)$. CV: Coeficiente de variação. Fonte: Autores.

Telles et al. (2005) trabalhando com cravo-de-defunto verificaram que o desenvolvimento das plantas em diferentes volumes de substrato e volumes dos recipientes, observaram que o volume de recipiente foi o item que mais influenciou a disponibilidade de nutrientes e água. De acordo com Filgueira (2013), o sucesso de qualquer produção comercial de hortaliças inicia-se com a produção de mudas, não sendo diferente para floríferas, pois tanto as hortícolas quando as espécies floríferas utilizam na produção de mudas técnicas semelhantes, ou seja, substrato de qualidade e cuidados com fertilização e água.

Para Trani et al. (2004), a produção de mudas é uma das etapas mais importantes do sistema produtivo, pois dela depende o desempenho final das plantas nos canteiros de produção, tanto do ponto de vista nutricional, quanto do tempo necessário à produção. Consequentemente, a qualidade das mudas contribue para o número de ciclos produtivos dentro de um ano agrícola, proporcionando resistência contra os danos mecânicos no momento do transplante, boa capacidade de adaptação ao novo ambiente, reduz o ciclo de produção e aumenta a resistência a doenças.

Verificou-se que a espessura do caule (Tabela1) obteve resultados similares ao número de folhas para os diferentes tratamentos, onde os tratamentos com adubações isoladas apresentaram espessura superior não diferindo entre si e diferindo dos demais tratamentos. A espessura das hastes é, também, um importante parâmetro a ser avaliado, pois hastes delgadas podem não suportar o peso das inflorescências, facilitando o seu tombamento e, causando aparência desarmônica no canteiro definitivo, assim não condizendo com a função das forrações que é de forrar totalmente o solo.

No sistema radicular, observou-se que o comprimento e massa verde das raízes (Tabela 1) tiveram comportamentos semelhantes para os tratamentos testemunha (T1) e com adubação por fertirrigação (T2), os quais apresentaram as maiores 
médias, em relação aos demais tratamentos. Esse comportamento é confirmado pelas notas de coesão do torrão (Tabela 1; Figuras 2 e 3), de 4,5 e 5,0 para os tratamento T1 e T2, respectivamente.

Figura 3 - Sistema radicular das mudas de alegria-de-jardim (Salvia splendens Ker Gawl.). a: T1(testemunha; sem adubação); b; T2 (adubação por fertirrigação com Fertilizante Misto Hakaphos Vermelho ${ }^{\circledR}$ (NPK 18-18-18)); c: T3 (adubação foliar com produto comercial Biosul ${ }^{\circledR}$ Fertilizantes (NK 08-05-08)), d: T4 (adubação por fertirrigação + foliar). Fonte: Autores (2020).

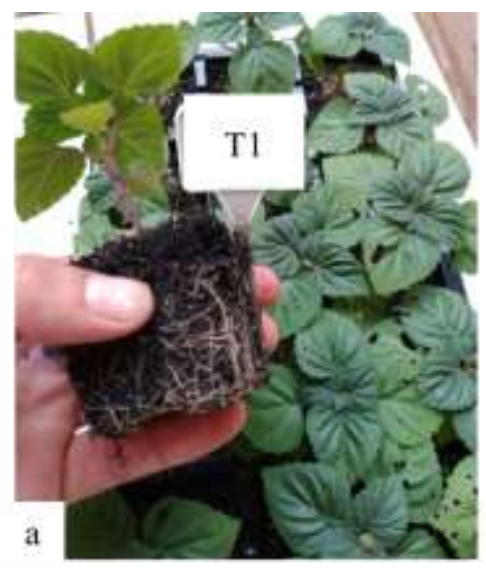

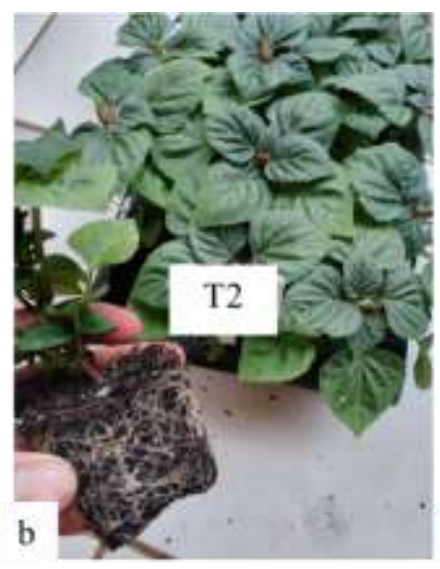
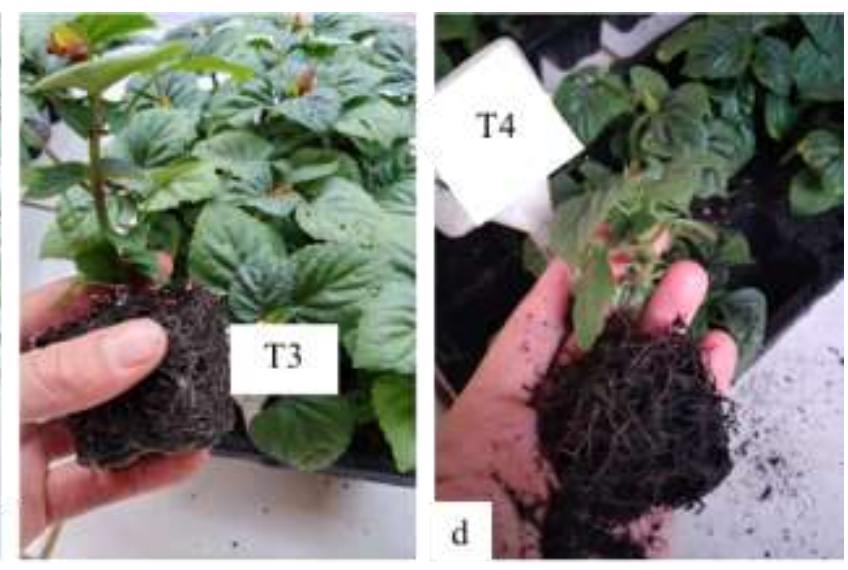

Fonte: Autores.

Para Menegaes et al. (2017), a escala de notas sobre a coesão de torrão é um parâmetro importante para a produção de mudas, por diversos fatores um deles diz respeito a qualidade do substrato em relação direta ao recipiente, que permitem o pleno desenvolvimento radicular. Também, é importante ressaltar que em bandejas o espaço para crescimento é restrito, assim as raízes tentem a sofrer estresse ambiental maior quando em situação de substrato inadequado ou falta de água e nutrientes. Salvador et al. (2001) relataram que em células de tamanho menor, em consequência da maior concentração de raízes, ocorre maior demanda de oxigênio e de remoção de $\mathrm{CO}_{2}$, assim as mudas produzidas em bandejas com células menores ficam mais vulneráveis ao estresse hídrico e nutricional pois a quantidade de substrato nem sempre é suficiente e com isso a coesão do torrão tende a ser inferior.

O estresse referido ao desenvolvimento das raízes, provavelmente está relacionado a salinização do substrato, uma vez que todos os tratamentos tinham o mesmo substrato não sendo dessa forma problemas relacionados as condições físicas do mesmo, a salinização em recipientes está relacionado a concentração de sais no substrato, sais esses vindo da adubação e da água de irrigação. Para Araújo e Machado (2006), o acúmulo de biomassa nas raízes é um processo muito importante, visto que o sucesso do transplante de mudas está relacionado com a estruturação do sistema radicular da planta, que por sua vez envolve-se na sustentação da mesma no solo, assim como na absorção de água e nutrientes.

\section{Conclusão}

As formas de adubação utilizadas influenciaram o desenvolvimento e a qualidade das mudas de alegria-de-jardim (Salvia splendens Ker Gawl.), sendo recomendado a adubação por fertirrigação para a produção de mudas de alegria-de-jardim em caixaria.

\section{Referências}

Alvarez, H. V. V., Ferreira, A. S., Alemparte, G. L. A. S. \& Morais, P. M. (2014). Fertilização de plantas ornamentais pelo método requerimento-suprimento: proposição de técnica experimental. Revista Brasileira de Ciência do Solo, 38(2), 532-543. 10.1590/S0100-06832014000200018. 
Araújo, A. P. \& Machado, C. T. T. (2006). Fósforo. In: Fernandes, M. S. (Ed.). Nutrição mineral de plantas. Viçosa, MG: Sociedade Brasileira de Ciência do Solo.

Bellé, R. A. (2011). Caderno didático: Floricultura: Flores e jardim. UFSM.

Caballero, R., Ordovás, J., Pajuelo, P., Carmona, E. \& Delgado, A. (2007). Iron chlorosis in gerbera as related to properties of various types of compost used as growing media. Communications in Soil Science and Plant Analysis, 38(1), 2357-2369. 10.1080/00103620701588494

Costa, P. C. (2003). Produção do tomateiro em diferentes substratos. Botucatu. (Tese de Doutorado em Agronomia).

Feletti, T. A. (2018). Efeito do volume de recipientes e adubação na qualidade de mudas de Paratecoma peroba Kuhlm. Jerônimo Monteiro. (Trabalho de Conclusão de Curso em Engenheiro Florestal).

Ferreira, D. F. (2014). Sisvar: A guide for is bootstrap procedures in multiple comparisons. Ciência e Agrotecnologia, 38(2), 109-112. 10.1590/S141370542014000200001

Filgueira, F. A. R. (2013). Novo Manual de Olericultura: agrotecnologia moderna na produção e comercialização de hortaliças. Viçosa: UFV.

Fresinghelli Netto, J. (2018). Efeito da irrigação e substrato no crescimento e produção da espécie Dianthus chinensis $L$. Alegrete. (Trabalho de Conclusão de Curso em Engenharia Agrícola). http://dspace.unipampa.edu.br/handle/riu/3292.

Girardi, L. B., Bellé, R. A., Rodrigues, M. A. \& Silva, L. O. (2012). Avaliação da qualidade da produção de amor perfeito produzido em bandejas plástica. Santa Maria: Jornada Acadêmica Integrada. https://www.ufsm.br/app/uploads/sites/346/2019/12/34-JAI_Final.pdf.

Junqueira, A. H., Peetz, M. S. (2017). Brazilian consumption of flowers and ornamental plants: habits, practices and trends. Ornamental Horticulture, 23(2), 115-120. 10.14295/oh.v23i2.1070.

Kämpf, A. N., Takane, R. \& Siqueira, P. T. V. (2006). Floricultura - técnicas de preparo de substratos. Brasília: Tecnologia Fácil.

Lopes, S. J., Brum, B., Santos, V. J., Melo, E. F., Santos, O. S. \& Couto, M. R. M. (2007). Área foliar e número de flores de nastúrcio sob duas densidades de plantio. Horticultura Brasileira, 25(2), 11-19. 10.1590/S0102-05362007000200006.

Lorenzi, H. (2013). Plantas para o jardim no Brasil. Nova Odessa: Instituto Plantarum, 2013.

Ludwig, F., Fernandes, D. M., Guerrero, A. C. \& Villas Bôas, R. L. (2013). Absorção de nutrientes em cultivares de gérbera cultivada em vaso. Horticultura Brasileira, 31(4), 622-627. 10.1590/S0102-05362013000400019.

Menegaes, J. F., Zago, A. P., Bellé, R. A. \& Backes, F. A. A. L. (2017). Enraizamento de estacas de forrações ornamentais em diferentes concentrações de ácido indolbutírico. Nativa, 5(5), 311-315. 10.31413/nativa.v5i5.4468.

Pires, A. A., Monnerat, P. H., Marciano, C. B., Pinto, L. G. R., Zampirolli, P. D., Rosa, R. C. C. \& Muniz, R. A. (2008). Efeito da adubação Alternativa do maracujazeiro-amarelo nas características químicas e físicas do solo. Revista Brasileira de Ciência do Solo, 32(5): 1997-2005. https://www.scielo.br/pdf/rbcs/v32n5/21.pdf.

Piroli, J. D. (2018). Produção de gérbera de corte (Gerbera jamesonii) em função de diferentes disponibilidades hídricas. Santa Maria. (Mestrado em Engenharia Agrícola). https://repositorio.ufsm.br/handle/1/13822.

Salvador, E. D., Paqual, M., \& Spera, M. R. N. (2001). Efeito de diferentes substratos no crescimento de samambaia-matogrossense (Polypodium aureum L.). Ciência Agrotécnica, 25(4), 10-16. https://www.scielo.br/scielo.php?script=sci_issuetoc\&pid=1413-705420030004\&lng=en\&nrm=iso.

Schmitz, J. A. K., Souza, P. V. D. \& Kämpf, A. N. (2002). Propriedades químicas e físicas de substratos de origem mineral e orgânica para o cultivo de mudas em recipientes. Ciência Rural, 32(1), 937-944. 10.1590/S0103-84782002000600005.

Telles, C. A., Mielk, É. C., Machado, M. P. \& Biase, L. A. (2005). Diferentes volumes de substrato no desenvolvimento de plantas de cravo de defunto (Targetes patula L). Revista Brasileira de Horticultura Ornamental, 11(1), 67-71.doi:10.14295/rbho.v11i1.31..

Terra, S. B. \& Züge, D. P. P. D. O. (2013). Floricultura: a produção de flores como uma nova alternativa de emprego e renda para a comunidade de Bagé- RS. Revista Conexão UEPG, 9(2), 1-5. https://dialnet.unirioja.es/servlet/articulo?codigo=4762159.

Trani, P. E., Novo, M. C. S. S., Cavallario Júnior, M. L. \& Teles, L. M. G. (2004). Produção de mudas de alface em bandejas e substratos comerciais. Horticultura Brasileira, 22(2), 290-294. 10.1590/S0102-05362004000200025. 